\title{
Crustal structure of the ocean-island arc transition at the mid Izu-Ogasawara (Bonin) arc margin
}

\author{
Azusa Nishizawa ${ }^{1}$, Kentaro Kaneda $^{1}$, Ayako Nakanishi $^{2}$, Narumi Takahashi ${ }^{2}$, and Shuichi Kodaira ${ }^{2}$ \\ ${ }^{1}$ Hydrographic and Oceanographic Department, Japan Coast Guard, Tokyo 104-0045, Japan \\ ${ }_{2}^{2}$ Japan Marine Science and Technology Center, Yokohama 236-0001, Japan
}

(Received April 25, 2006; Revised July 6, 2006; Accepted July 12, 2006; Online published September 15, 2006)

\begin{abstract}
Wide-angle refraction experiments were conducted to reveal the crustal structure at the transition between the intra-oceanic island arc crust of the mid Izu-Ogasawara (Bonin) arc and the backarc oceanic crust of the Shikoku Basin. The island arc crust consists of an upper crust about $5 \mathrm{~km}$ thick with a $P$-wave velocity $<6.0 \mathrm{~km} / \mathrm{s}$, a middle crust $5 \mathrm{~km}$ thick with a $P$-wave velocity of $6.0-6.3 \mathrm{~km} / \mathrm{s}$, and a lower crust $10 \mathrm{~km}$ thick with a $P$-wave velocity of $6.8-7.2 \mathrm{~km} / \mathrm{s}$. The total crustal thickness is about $20 \mathrm{~km}$. The thickness thins to approximately 6 $\mathrm{km}$ over a distance of $30 \mathrm{~km}$ at the western margin of the Izu-Ogasawara arc (IOA). These features are very similar to those of the northern IOA, which indicates that the crustal structure is relatively constant within 200 $\mathrm{km}$ at the northern and mid IOA. The Kinan Escarpment, a 500-km-long fault with a maximum offset of $800 \mathrm{~m}$, characterizes the transition zone between the IOA and Shikoku Basin. The seismic crustal model indicates that the escarpment is a fault which tears the whole oceanic crust along the western margin of the IOA. However, no significant differences exist in the crustal structure on either side of the escarpment, and the Kinan Escarpment seems to be a zone of the structural weakness from its birth.
\end{abstract}

Key words: Mid Izu-Ogasawara (Bonin) arc, Kinan Escarpment, $P$-wave velocity structure.

\section{Introduction}

The Izu-Ogasawara (Bonin) island arc-trench-backarc system is located on the Philippine Sea plate along with the Izu-Ogasawara Trench (Fig. 1(a)). The Izu-Ogasawara Island arc (IOA) is formed by the Pacific plate subduction beneath the Izu-Ogasawara trench, and the Shikoku Basin (SB) was produced as a backarc basin. The IOA crustal model as an intra-oceanic island arc was obtained at the northern part of the $\operatorname{arc}$ at $32^{\circ} 15^{\prime} \mathrm{N}$ by Suyehiro et al. (1996) and Takahashi et al. (1998). The arc crust is characterized by a middle crust with a $P$ velocity of $6 \mathrm{~km} / \mathrm{s}$, a lower crust with a $P$-wave velocity of $7.1-7.3 \mathrm{~km} / \mathrm{s}$, and a total crustal thickness of about $20 \mathrm{~km}$. The transitional region from the IOA crust to the SB oceanic crust in their model shows that the crustal thickness decreases from 20 to $6 \mathrm{~km}$ within a distance of about $30 \mathrm{~km}$. However, this estimation was based on only two ocean bottom seismographs (OBS) on the SB, and the transition structure was less resoluble.

Seafloor topography at the transition along the western margin of the IOA is distinct in the existence of a 500$\mathrm{km}$-long submarine escarpment. This is called the Kinan Escarpment (KE) and is downthrown to the west with offsets of 500-800 $\mathrm{m}$ and extends from north to south (Kasuga and Ohara, 1997). The orientations of the seafloor fabric and magnetic anomaly are different between the east and west sides of the escarpment. Kasuga and Ohara (1997) suggested that the KE is a large normal fault formed by

Copy right(c) The Society of Geomagnetism and Earth, Planetary and Space Sciences (SGEPSS); The Seismological Society of Japan; The Volcanological Society of Japan; The Geodetic Society of Japan; The Japanese Society for Planetary Sciences; TERRAPUB. a post-spreading deformation of the SB lithosphere along the mechanical boundary between the active "buoyant" IOA and inactive "isostatically sinking" SB. If this hypothesis is correct, the crustal structure might be different in both sides of the KE, and materials supporting the "buoyancy" might exist to the east of the escarpment.

The study of the structure and composition of island arc margins provides insight into the mechanism of backarc rifting and its evolution to seafloor spreading. However, there is no wide-angle seismic experiment focusing on the transition from the Shikoku back-arc basin to IzuOgasawara intra-oceanic island arc. We conducted two wide angle seismic experiments at around $30^{\circ} \mathrm{N}$, about 150 $\mathrm{km}$ south of the previous study (Suyehiro et al., 1996; Takahashi et al., 1998), in order to elucidate the variation in the seismic velocity models along the arc axis. Since the seafloor topography showing the KE is clearly identifiable at $30^{\circ} \mathrm{N}$, we were able to examine the crustal structure related to the escarpment beneath the transition zone between the IOA and SB.

\section{Data Acquisition and Processing}

The first of two wide-angle seismic experiments was carried out as a joint operation between the Hydrographic and Oceanographic Department, Japan Coast Guard (HODJ) and the Japan Marine Science and Technology Center (JAMSTEC) in April-May, 2002. In this investigation, we deployed 25 OBS at intervals of $20-30 \mathrm{~km}$ along an $\sim 800$ $\mathrm{km}$ track-line at $30-31^{\circ} \mathrm{N}$ from the Pacific Basin at its eastern end, through the IOA and KE, to the center of the Shikoku Basin at its western end, except for the areas of 


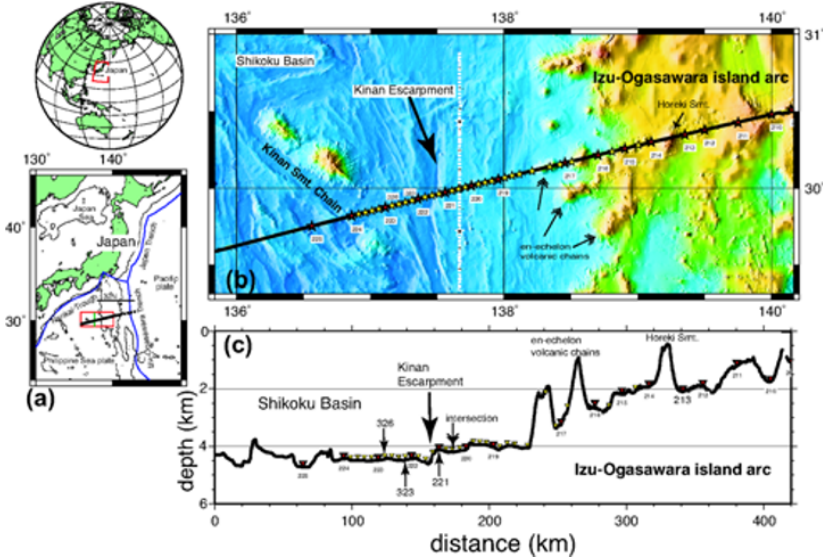

Fig. 1. (a) Location of the seismic profile (thick solid line) at the transition between the Shikoku Basin and mid Izu-Ogasawara island arc. Line $32 \mathrm{~N}$ is the profile conducted by Suyehiro et al. (b) The OBS positions in this study are shown by asterisks on the shaded bathymetric map. (c) Depth profile along the line. Inverted triangles indicate OBSs. Larger symbols are OBSs for the 2002 experiment, and smaller ones for 2003. Numerals indicate the station name. The Kinan Escarpment is shown by a large arrow.

the Izu-Ogasawara Trench exceeding $6000 \mathrm{~m}$ depth. The deployment and retrieval of OBSs were carried out by the $S / V$ Shoyo, HODJ. The seismic source is an array of eight $1500-$ inch $^{3}$ (24.61) air guns provided by the R/V Kairei belonging to JAMSTEC, firing every $90 \mathrm{~s}$ at an with approximate spacing at $200 \mathrm{~m}$. Due to poor OBS coverage and a deviation of the profile track from a straight line in the eastern part of the profile, we used the data within $400 \mathrm{~km}$ from the western end of the profile in this paper (northeast to southwest line in Fig. 1(b)).

The second experiment was carried out in May 2003. Thirty OBSs were deployed at 5-km intervals centered on the $\mathrm{KE}$ at the middle of the profile (same line as that of the 2002 experiment). A non-tuned airgun array with a total capacity of $6000 \mathrm{inch}^{3}$ (98.3 l) was shot at 100-m intervals by the $S / V$ Shoyo.

Each OBS used in both experiments contained a threecomponent 4.5-Hz geophone and a hydrophone (Shinohara et al., 1993; Kanazawa and Shiobara, 1994). We used output of the vertical sensors to produce record sections because of their high quality. Navigation was provided by the ship's differential Global Positioning System, and each OBS instrument was relocated using the direct water wave arrivals.

The OBS data were processed through frequency filtering, deconvolution, and slant stack for increasing signal-tonoise ratio. An example of a record section at OBS 213 on the IOA is shown in Fig. 2(a). For the first step of the seismic modeling, the thickness of the top-most sediments is constrained by multi-channel seismic data (Park et al., 2002). Tomographic inversion of GeoCT II (Zhang et al., 1998) was then applied to the first arrival data. Although the crustal model of the Shikoku Basin could be estimated by the tomographic inversion, it was difficult to determine the deeper part of the island-arc crust only by the inversion owing to the sparse ray density. The ray diagram for all of the rays in the inversion is shown in Fig. 3(b). The

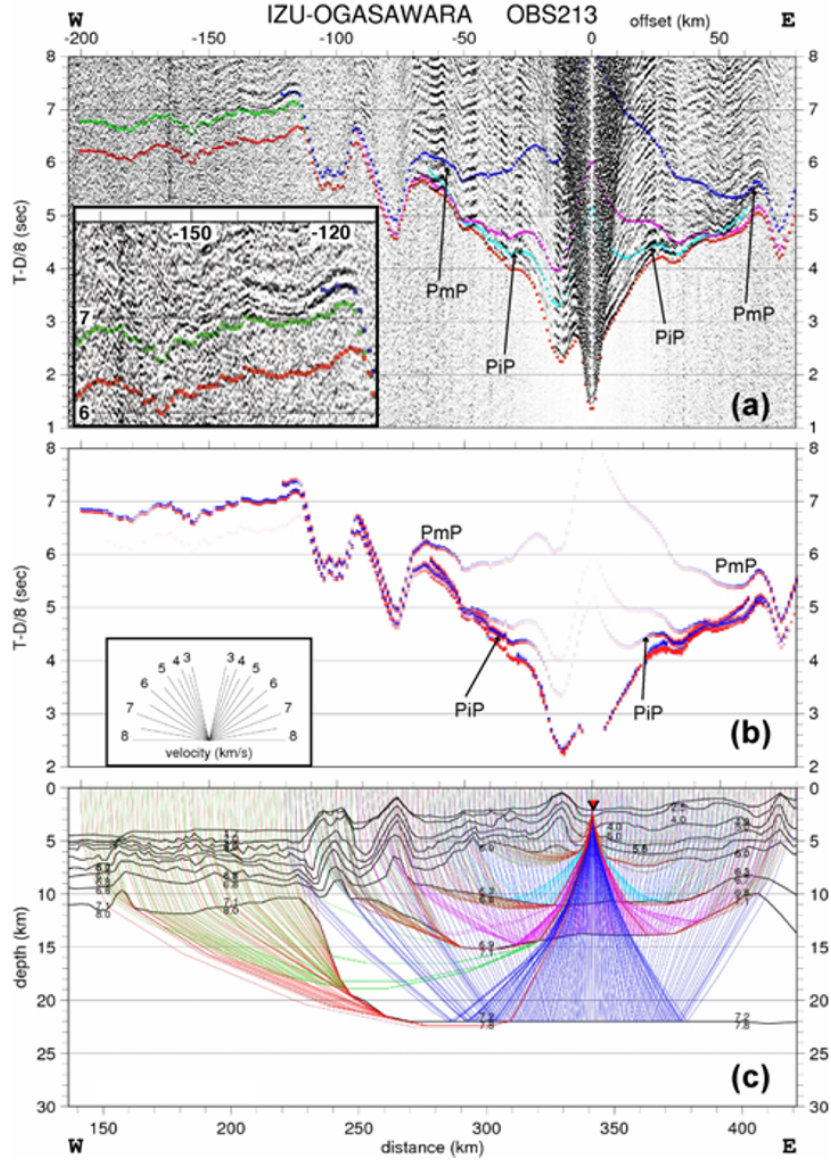

Fig. 2. (a) Vertical geophone record section for OBS 213. The data were processed through predictive deconvolution and band-pass filtered (4-20 Hz). A gain factor proportional to distance has been used to enhance the distant seismograms. The reduction velocity is $8 \mathrm{~km} / \mathrm{s}$. Small dots indicate calculated travel times. Left: A blowup of the record section with offsets of $-110 \sim-175 \mathrm{~km}$ and times of $6 \sim 8 \mathrm{~s}$. (b) Synthetic seimograms for OBS 213 calculated by ray tracing the velocity model in Fig. 3. Arrivals with large amplitude are shown in darker tone. (c) Ray geometry through the transition zone and island-arc crust for OBS 213. The top layer is water.

root-mean-square misfit between the observed and calculated travel times was $90 \mathrm{~ms}$.

Finally, we took the inversion result as an initial model for two-dimensional ray tracing and conducted forward modeling of RAYINVR (Zelt and Ellis, 1988) and a second forward modeling application using graph theory in ray tracing algorithm (Kubota et al., 2005). Therefore, the final model is basically developed with the interactive ray tracing by trial and error. The misfits between observed and calculated travel times are generally within $50 \mathrm{~ms}$ except for distant arrivals and reflection signals. The 2-D ray theoretical amplitudes were performed to test and verify specific model features.

\section{Results}

The 2-D $P$-wave velocity model at the mid IOA transition is shown in Fig. 3. This structural model reveals that the IOA crust is up to $22 \mathrm{~km}$ deep and that there is a thickmore than $10 \mathrm{~km}$-lower crust with a velocity of $6.8-7.2$ $\mathrm{km} / \mathrm{s}$. A velocity discontinuity between the $6.0-6.3 \mathrm{~km} / \mathrm{s}$ middle crust and the $6.8-7.2 \mathrm{~km} / \mathrm{s}$ lower crust at a depth of 

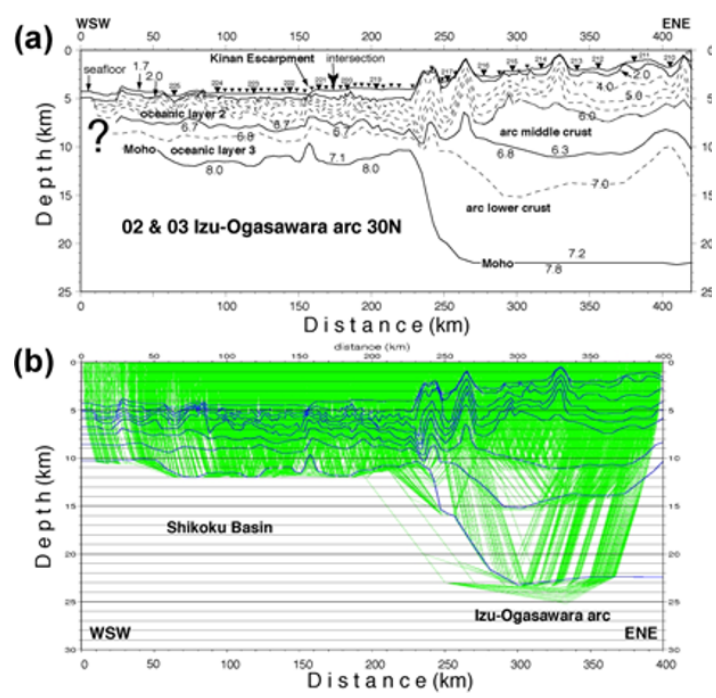

Fig. 3. (a) $P$-wave velocity model. The locations of the OBSs are shown by inverted triangles. Larger symbols are OBSs for the 2002 experiment, and smaller ones for 2003. The thick line indicates layer boundary, the thin line is the iso-velocity line and a label on a line shows its velocity. The area to the west of the OBS 225 was unresolvable owing to a lack of rays. The boundary between oceanic layer 2 and layer 3 is not a velocity gap but a discontinuity of the velocity gradient. On the other hand, the boundary between the middle and lower arc crust is velocity discontinuity. The position of the intersection between the EW profile and auxiliary NS profile is shown by a double arrow. (b) Ray diagram for tomographic inversion.

$10 \mathrm{~km}$ is plausible, since several observed record sections show the reflection signals from the boundary. For example, we can identify the reflection signals (PiP in Fig. 2(a)) in the western part of OBS 213. PmP signals from the Moho of the island arc crust are also observed at some OBSs. PmP arrivals around $+60 \mathrm{~km}$ in Fig. 2(a) can be explained within an error of $0.3 \mathrm{~s}$, but PmP signals in the western part of OBS 213 are not clear. This may be due to lateral inhomogeneity of the Moho.

There are several en-echelon volcanic chains trending in the NE-SW direction on the western margin of the IOA (Fig. 1(b)). High-velocity materials ascending at the bathymetric highs are needed to explain the observed travel times. The crustal thickness changes from $20 \mathrm{~km}$ at the IOA to $6 \mathrm{~km}$ at the SB over a horizontal range of about $30 \mathrm{~km}$ (Fig. 3). Actually, the position of the transition is not well constrained from only the first arrivals propagating in the transition zone since their amplitudes are too small to pick their arrival times with high accuracy. However, relatively large-amplitude signals observed at the western offset at around $-120 \mathrm{~km}$ in Fig. 2(a) are interpreted as refracted later arrivals propagated through the arc lower crust and transition zone. Their calculated travel times and amplitudes reasonably fit the observations (Fig. 2(a) and (b)).

An example of the results on the OBSs on the SB is shown in Fig. 4 and indicates characteristics of a normal oceanic crust. The KE is positioned $160 \mathrm{~km}$ eastward from the western end of the profile and shows a large vertical displacement of over $600 \mathrm{~m}$ in water depth. The crustal model beneath the escarpment is irregular throughout the entire crust. Travel time differences due to the presence or absence of an uneven shape of the Moho around the
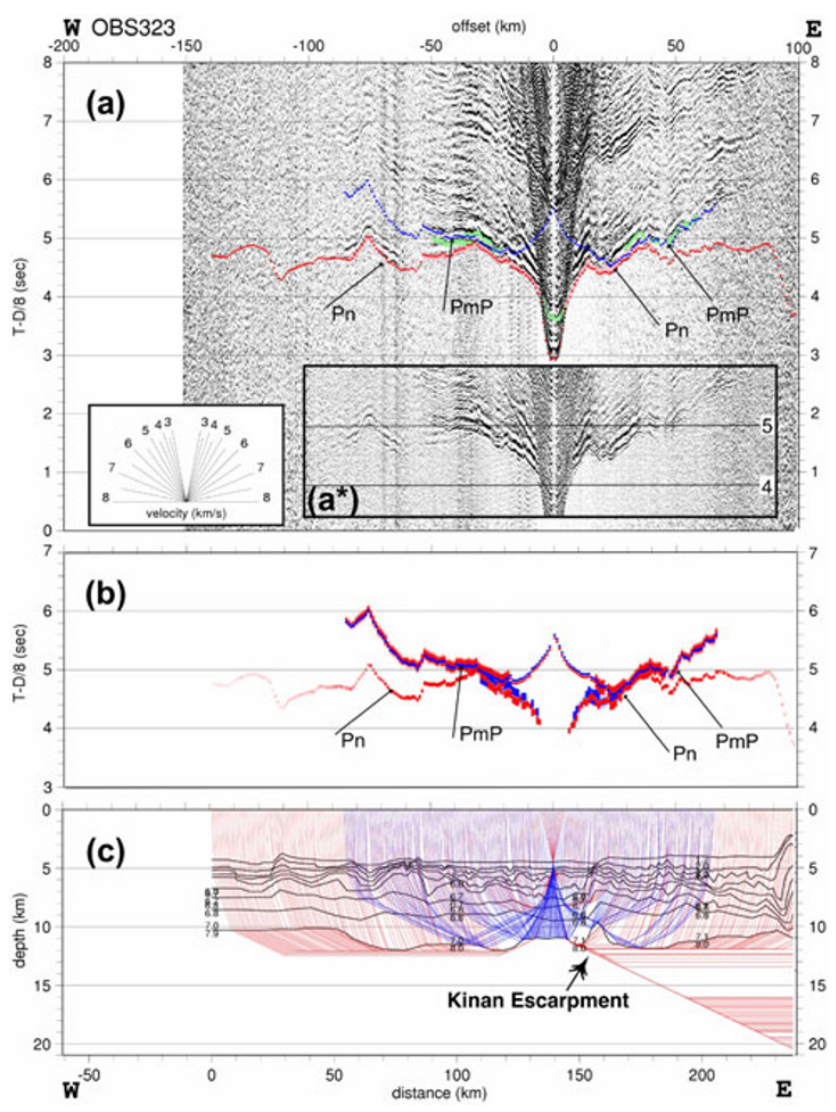

Fig. 4. (a) Vertical geophone record section for OBS 323 on the Shikoku Basin. Small dots indicate calculated travel times. Pink and green lines are picked arrival times for first and later phases, respectively. $\left(\mathrm{a}^{*}\right)$ A part of the same record section but no superposition. (b) Synthetic seimograms. (c) Ray geometry.

escarpment are comparable to the average travel time fitting error within $0.1 \mathrm{~s}$. Figure 5 shows the comparison of the record section and ray diagram for the irregular Moho and flat Moho model, respectively. The irregular Moho model reveals a better fit than the flat Moho model.

\section{Discussion}

The $P$-wave velocity model beneath the mid IOA at around $30^{\circ} \mathrm{N}$ obtained in this study closely resembles that of the northern IOA at $32^{\circ} 15^{\prime} \mathrm{N}$ (Suyehiro et al., 1996; Takahashi et al., 1998). The layer structure of the island arc at $30^{\circ} \mathrm{N}$ - that is, the number of layers and the thickness and velocity of each-is very similar to that at $32^{\circ} 15^{\prime} \mathrm{N}$. Therefore, this crustal structure continues from $32^{\circ} 15^{\prime} \mathrm{N}$ to the southward at least $30^{\circ} \mathrm{N}$, although the water depth along the IOA becomes gradually larger from north to south. Hino (1991) demonstrated that the thickness of $P$-wave velocity of $6 \mathrm{~km} / \mathrm{s}$ materials increases from $29^{\circ} \mathrm{N}$ to $33^{\circ} \mathrm{N}$ in the forearc area and suggested that the IOA crust is more mature toward the north. Our results show that there is no noteworthy variation in the arc crust structure in the $30^{\circ}-32^{\circ} 15^{\prime} \mathrm{N}$ area. Since the water depth along the island arc changes greatly a little south of our profile, the crustal thickness should decrease to the south.

The largest change in crustal thickness along the profile occurs at a distance of $230 \mathrm{~km}$ from the western end of 


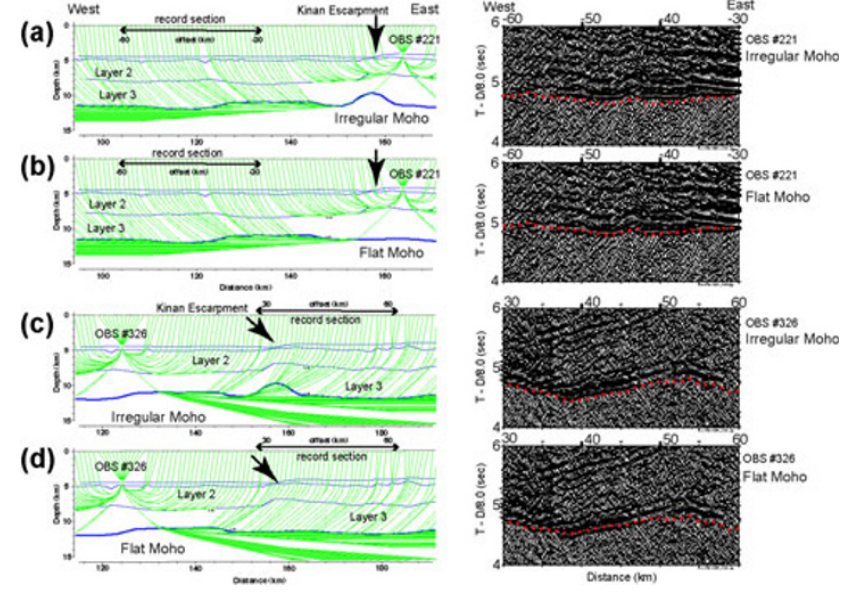

Fig. 5. Comparison of a ray-diagram (left figure), observed record section, and calculated travel times shown by dots (right). The Kinan Escarpment is marked by a large arrow. The offset range of the record section in the right figure corresponds to the distance range limited by a horizontal arrow in the left figure. (a) For OBS 221 with irregular Moho shape beneath the Kinan Escarpment, (b) OBS 221 with flat Moho, (c) OBS 326 with Moho irregularity, (d) OBS 326 with flat Moho.

the profile, where the crust is the thinnest. Rather high $V_{p}>7 \mathrm{~km} / \mathrm{s}$ materials are often found around the Moho at rifted continental margins, and they are interpreted to be magmatic underplating or serpentinized mantle (e.g. Dean et al., 2000). There is no clear evidence indicating such a distinct high velocity within the transition region where the seismic rays exist in Fig. 3 (b). The width of the transition zone in the crustal thickness is about $30 \mathrm{~km}$. Although it is difficult to constrain the width only by the seismic data, 2D gravity modeling supports the position where the crustal thickness changes and the width of the transition zone is $30 \pm 10 \mathrm{~km}$.

Kobayashi (1984) presumed that the shallower igneous basement depth of the eastern margin of SB compared with the western margin may be due to the abnormally thick lowvelocity and low-density zone linked to the active IOA, underlain by the hot magma existing above the subducting slab. The obtained crustal thickness within $30 \mathrm{~km}$ east of the $\mathrm{KE}$ is about $8 \mathrm{~km}$ and rather thick compared with the crust farther east at distances of 200-230 km. This somewhat thicker crust continuously exists within a range of 100 $\mathrm{km}$ parallel to the KE, which is confirmed by the auxiliary north-south profile using only three OBSs intersecting with the east-west profile as shown in Fig. 1(b). However, the average thickness for normal oceanic crust in the world is estimated to be $7.1 \pm 0.8 \mathrm{~km}$ by White et al. (1992), and the velocity structures of both sides within $50 \mathrm{~km}$ from the KE are not significantly different. Although the crustal irregularity beneath the KE is presumed to extend from the shallow crust to the Moho and the KE seems to be a fault that tears the whole oceanic crust, a characteristic crust supporting buoyancy to the east of the KE is not detected. Therefore, the KE corresponds to a zone of possible structural weakness related to an abrupt change in the topographic fabric and magnetic lineations of the seafloor, as inferred by Kasuga and Ohara (1997), and seems to be formed by nature at birth.
These 2002 and 2003 seismic explorations in this study were conducted as preliminary/pilot experiments of the national continental shelf survey project of Japan. A number of full-dress seismic surveys with higher specifications will continue to be carried out in the Western Pacific region under the project until 2007 (Nishizawa, 2006). Integration of all these results including along arc variation in the crustal structure of the IOA and its margin will provide significant clues to construct island-arc and backarc basin evolution models.

Acknowledgments. The authors gratefully acknowledge the members of Continental Shelf Surveys Office, HODJ for the 2002 and 2003 marine seismic operation. Drs. K. Suyehiro, W. Soh and Y. Kaneda, JAMSTEC and Mr. S. Tani, HODJ coordinated a series of the experiments. Drs. R. Kubota and E. Nishiyama, Kawasaki Geol. Engin. Corp. Ltd., helped with the 2-D tomographic inversion and ray-tracing. The comments and suggestions from Mr. Kasuga, HODJ were greatly appreciated. We thank an anonymous reviewer and Prof. G. Moore for their helpful reviews of this paper. Most of the figures in this paper were made using the GMT graphic package of Wessel and Smith (1998).

\section{References}

Dean, S. M., T. A. Minshull, R. B. Whitmarsh, and K. E. Louden, Deep structure of the ocean-continent transition in the southern Iberia Abyssal Plain from seismic refraction profiles: The IAM-9 transect at $40^{\circ} 20^{\prime}, J$. Geophys. Res., 105, 5859-5885, 2000.

Hino, R., A study on the crustal structure of the Izu-Bonin arc by airgunOBS seismic profiling, Dr. Sci. Thesis, Tohoku University, 1991.

Kanazawa, T. and H. Shiobara, A newly developed ocean bottom seismometer, Japan Earth Planet. Sci. Joint Meeting, 341, 1994 (in Japanese).

Kasuga, S. and Y. Ohara, Evolution of the escarpments located in the back-arc basins in the southern waters of Japan-Mechanical boundary between sinking back-arc basins and buoyant active island arcs, Rep Hydrogr. Res., 33, 39-51, 1997 (in Japanese with English abstract).

Kobayashi, K., Subsidence of the Shikoku Back-arc basin, Tectonophysics, 102, 105-117, 1984.

Kubota, R., E. Nishiyama, K. Murase, and J. Kasahara, Fast computation algorithm of ray-paths and their travel times including later arrivals for a multi-layered earth model, Eos Trans. AGU, 86(52), Fall Meet. Suppl., Abstract, S41A-0966, 2005.

Nishizawa, A., Seismic exploration for the Japanese legal continental shelf, Japan Geoscience Union Meeting, Abstract, U051-013, 2006.

Park, J., T. Tsuru, N. Takahashi, S. Kodaira, and Y. Kaneda, Seismic Reflection Image Across the Izu-Bonin Island Arc System, Eos Trans. $A G U$, 83(47), Fall Meet. Suppl., Abstract, T72A-1224, 2002.

Shinohara, M., K. Suyehiro, S. Matsuda, and K. Ozawa, Digital recording ocean bottom seismometer using portable digital audio tape recorder, J. Jpn. Soc. Mar. Surv. Tech, 5, 21-31, 1993 (in Japanese with English abstract).

Suyehiro, K. et al., Continental crust, crustal underplating, and low-Q upper mantle beneath an oceanic island arc, Science, 272, 390-392, 1996.

Takahashi, N., K. Suyehiro, and M. Shinohara, Implications from the seismic crustal structure of the northern Izu-Bonin arc, The Island Arc, 7, 383-394, 1998.

Wessel, P. and W. H. F. Smith, New, improved version of the Generic MappingTools released, EOS. Trans. AGU, 79, 579, 1998.

White, R. S., D. McKenzie, and R. K. O'Nions, Oceanic crustal thickness from seismic measurements and rare earth element inversions, J. Geophys. Res., 97, 19683-19715, 1992.

Zelt, C. A. and R. M. Ellis, Practical and efficient ray tracing in twodimensional media for rapid travel-time and amplitude forward modeling, Can. J. Explor. Geophys., 24, 16-31, 1988.

Zhang, J., U. S. ten Brink, and M. N. Toksoz, Nonlinear refraction and reflection travel time tomography, J. Geophys. Res., 103, 29743-29758, 10.1029/98JB01981, 1998.

A. Nishizawa (e-mail: azusa@jodc.go.jp), K. Kaneda, A. Nakanishi, N. Takahashi, and S. Kodaira 